\title{
Short communication: Quantitative PCR coupled with sodium dodecyl sulfate and propidium monoazide for detection of culturable Escherichia coli in milk
}

\author{
Lei Dong, ${ }^{1,2,3 *}$ Huimin Liu, ${ }^{1,2,4 *}$ Lu Meng, ${ }^{1,2}$ Mengru Xing, ${ }^{1,2,3}$ Tu Lan, ${ }^{1,2,4}$ Mei Gu, ${ }^{1,2}$ Nan Zheng, ${ }^{1,2}$ Cheng Wang, ${ }^{4}$ \\ He Chen, ${ }^{4}$ and Jiaqi Wang ${ }^{1,2} \dagger$ \\ ${ }^{1}$ Laboratory of Quality and Safety Risk Assessment for Dairy Products of Ministry of Agriculture and Rural Affairs, Institute of Animal Science, \\ Chinese Academy of Agricultural Sciences, Beijing 100193, P. R. China \\ ${ }^{2}$ Milk and Dairy Product Inspection Center of Ministry of Agriculture and Rural Affairs, Beijing 100193, P. R. China \\ ${ }^{3}$ College of Food Science and Engineer, Qingdao Agricultural University, Qingdao 266109, P. R. China \\ ${ }^{4}$ Institute of Quality Standard and Testing Technology, Xinjiang Academy of Agricultural Sciences, Urumqi 830091, P. R. China
}

\section{ABSTRACT}

Escherichia coli has been frequently reported as a major foodborne bacterium contaminating raw milk or pasteurized milk. Therefore, the aim of this study was to explore a quantitative real-time PCR (qPCR) technique combined with sodium dodecyl sulfate (SDS) and propidium monoazide (PMA) to detect culturable E. coli in milk. An internal amplification control was also added into this reaction system as an indicator of false-negative results. The inclusivity and exclusivity of the primers were tested using DNA from $7 E$. coli and 14 other bacterial strains. The concentrations of SDS and PMA were determined according to plate counts and quantitative cycle values of qPCR, respectively. A standard curve was established using series diluted E. coli DNA. The reliability and specificity of this method were further determined by the detection of $E$. coli in spiked milk. The results showed that the optimal concentrations of SDS and PMA were $100 \mu \mathrm{g} /$ $\mathrm{mL}$ and $40 \mu M$, respectively. A standard curve with a good linear relationship (coefficient of determination $=$ 0.997; amplification efficiency $=100.5 \%$ ) was obtained. Compared with conventional PCR and PMA-qPCR, the SDS-PMA-qPCR assay was more specific and sensitive in culturable $E$. coli detection. Therefore, we evaluated and improved the SDS-PMA-qPCR method for detecting culturable E. coli in milk.

Key words: propidium monoazide, sodium dodecyl sulfate, Escherichia coli, quantitative real-time PCR, internal amplification control

\footnotetext{
Received July 16, 2018.

Accepted April 22, 2019.

*These authors contributed equally to this work.

$\nmid$ Corresponding author: jiaqiwang@vip.163.com
}

\section{Short Communication}

Escherichia coli is a high-risk food contaminant implicated in many outbreaks associated with raw milk (Wang et al., 2013) or pasteurized milk (Farrokh et al., 2013). Escherichia coli is also an indicator of fecal contamination, which plays an essential role in the quality and safety of milk products and other foods (Maheux et al., 2009).

Traditional culture-based detection methods, including enrichment, selection, and biochemical identification, confirmation, and toxin testing, are time consuming and laborious (Wang et al., 2015). Therefore, accurate and rapid methods for detecting E. coli are in urgent demand. The quantitative PCR (qPCR) technique, a promising method to identify and quantify foodborne pathogens effectively and rapidly in food products, is unable to distinguish viable cells from dead ones. The DNA from dead cells also serve as a qPCR template during the amplification phase, which could cause inaccurate quantification of the actual bacterial level of contamination (Zhang et al., 2014).

Propidium monoazide (PMA)-qPCR assay, which is based on the ability of PMA to selectively penetrate the dead cells and binds to DNA to inhibit DNA amplification in qPCR assay (Nocker and Camper, 2009; Varma et al., 2009; Fittipaldi et al., 2012), can remove the interference of dead cells (Nocker et al., 2006). Sodium dodecyl sulfate, a surfactant that can increase the permeability of dead cells to PMA without compromising the viability of live cells (Takahashi et al., 2017), can be used to treat E. coli along with PMA to eliminate falsepositive results. To reduce the possible interference of different PCR inhibitors, the DNA of Bacillus cereus was used as an internal amplification control (IAC) to serve as an indicator of false negatives.

According to current laws and standards in China and New Zealand (National Health and Family Planning Commission of PRC, China Food and Drug Ad- 
Table 1. Bacteria strains used for specificity test of primers

\begin{tabular}{llll}
\hline Bacterial species & Strain ID & Source $^{1}$ & PCR result \\
\hline Escherichia coli & ATCC10536 & ATCC & + \\
& ATCC43895 & ATCC & + \\
& ATCC43889 & ATCC & + \\
& ATCC43888 & ATCC & + \\
& ATCC25922 & ATCC & + \\
Cronobacter muytjensii & CMCC44102 & CMCC & + \\
Salmonella enterica ssp. enterica & CMCC44103 & CMCC & + \\
Enterococcus faecalis & ATCC51329 & ATCC & - \\
Bacillus cereus & ATCC14028 & ATCC & - \\
Lactobacillus plantarum & ATCC29212 & ATCC & - \\
Streptococcus salivarius ssp. thermophilus & ATCC11778 & ATCC & - \\
Shigella flexneri & ATCC8014 & ATCC & - \\
& ATCC14485 & ATCC & - \\
Shigella sonnei & ATCC12022 & ATCC & - \\
Shigella boydii & CMCC51240 & CMCC & - \\
Shigella dysenteriae & CMCC51572 & CMCC & - \\
${ }^{1}$ ATCC $=$ American Type Culture Collection; CMCC ATC25931 & ATCC & - \\
& ATCC25931 Cenal Center for Medical Culture Collections.
\end{tabular}

ministration, 2016; New Zealand Food Safety Authority, 2008), the plate count method is the only way to quantify culturable bacteria. To solve the problem of time-consuming and tedious methods, the development of new rapid detection methods is imperative. Until now, few publications have reported SDS and PMA coupled with qPCR to detect $E$. coli in milk. Therefore, the aim of this assay was to improve and evaluate a SDS-PMA-qPCR method to rapidly detect and quantify culturable E. coli cells in milk.

The bacterial strains used in this study are listed in Table 1. All bacterial strains were grown at $37^{\circ} \mathrm{C}$ in nutrient broth (Beijing Land Bridge Technology Ltd., Beijing, China) and then DNA extraction was performed as described in Dong et al. (2018).

Inclusivity and exclusivity tests were studied using a panel of 21 strains, including 7 E. coli standard strains and 14 other gram-positive or gram-negative species that are foodborne pathogens (Table 1). The PCR assay was carried out as described in Dong et al. (2018) with the primers changed. The primers of $E$. coli were 5'-ACCAGACCCAGCACCAGATAAG-3' and 5'-CTGCTTCTTTAAGCAACTGGCGA-3', and the probe was 5'FAM-CATACATATTGCCCGCCAGTACAGACBHQ3' and 5'FAM-CATACATATGCCCGCCAGACAGAC-BHQ3' (Pavlovic et al., 2011). The sequences of IAC used were 5'-CGCAAGGCTGAAACTCAAAG-3' and 5 '-GAGGATGTCAAGACCTGGTAAG, and the probe was 5'-ACAAGCGGTGGAGCATGTGGTTTA-3' (Li et al., 2015). All the primers and probes were synthesized by Shanghai (China) Sangon Biological Engineering Technology \& Services Co., Ltd.
The SDS and PMA treatments were performed according to Dong et al. (2018), with slight modifications. The viability of bacteria in the SDS solutions with final concentrations of $0,25,50,100,200,250,500$, and $1,000 \mu \mathrm{g} / \mathrm{mL}$ was examined on appropriate plates. The optimized condition of SDS was chosen by maximizing SDS concentration inhibiting the amplification of dead E. coli without sacrificing the culturable cells. The PMA (Biotium Inc., Hayward, CA) treatment was done with cell mixtures prepared by mixing $1 \mathrm{~mL}$ of culturable cells with $1 \mathrm{~mL}$ of dead cells followed by an optimized concentration of SDS treatment. In this assay, the optimized PMA condition was examined with 5 concentrations $(0,10,20,30,40$, and $50 \mu M)$. The minimal PMA concentration with maximal quantitative cycle $(\mathbf{C q})$ value was accepted as the optimal PMA conditions. The genomic DNA were used as template DNA for qPCR methods.

To determine amplification efficiency and sensitivity of the SDS-PMA-qPCR method, a standard curve was prepared using serial 10-fold dilution suspensions of genomic DNA isolated from culturable E. coli (ATCC25922) grown until the stationary growth phase $\left(1.2 \times 10^{1}\right.$ to $\left.1.2 \times 10^{7} \mathrm{cfu} / \mathrm{mL}\right)$. The corresponding cfu were calculated using plate counting of the sample. The different bacterial concentrations were plotted against the corresponding $\mathrm{Cq}$ values. The slope of the curve and the linear relationship were automatically calculated with Bio-Rad CFX Manager 3.1 (Bio-Rad).

The UHT milk (Mengniu, Inner Mongolia, China) was purchased from a local supermarket in Beijing and was used in the spiking studies. It was confirmed nega- 
tive for $E$. coli by standard culturing in nutrient agar plates. To test the feasibility of SDS-PMA-qPCR assay to exclude the interference of dead bacteria, the milk samples were divided into 3 groups and inoculated with $3 \times 10^{2} \mathrm{cfu} / \mathrm{mL}$ of culturable cells, $3 \times 10^{2} \mathrm{cfu} / \mathrm{mL}$ of culturable cells with $3 \times 10^{3} \mathrm{cfu} / \mathrm{mL}$ of dead cells, and $3 \times 10^{3} \mathrm{cfu} / \mathrm{mL}$ of culturable cells with $3 \times 10^{2} \mathrm{cfu} /$ $\mathrm{mL}$ of dead cells, respectively. Then the samples were treated with or without optimal SDS and PMA. After SDS and PMA treatment, the DNA was extracted using the cetyltrimethylammonium bromide method for qPCR. All tests were repeated 3 times.

To verify the specificity of the primers and probes, interference of nontarget bacteria during the amplification of the primers was determined by conventional PCR in the presence of DNA from 21 strains. As shown in Table 1, only DNA of E. coli were positively identified, whereas the nontarget bacterial strains including Cronobacter muytjensii, Salmonella enterica ssp. enterica, Enterococcus faecalis, Shigella flexneri, Shigella sonnei, Shigella boydii, Shigella dysenteriae, Staphylococcus aureus, B. cereus, Lactobacillus plantarum, and Streptococcus salivarius ssp. thermophilus were negative in PCR reactions. These results indicated that the primers used in this SDS-PMA-qPCR assay had the anticipated high specificity.

Tolerance of E. coli to SDS was studied. The mean bacterial numbers on plates with different concentrations of SDS treatment were determined (Figure 1). For SDS concentrations of $0,25,50$, and $100 \mu \mathrm{g} / \mathrm{mL}$, the log cfu values were $7.07,7.07,7.06$, and 7.06 , respectively. When the SDS concentrations were 200, 250, 500, and $1,000 \mu \mathrm{g} / \mathrm{mL}$, the $\log$ cfu values were $6.95,6.93,6.89$, and 6.79 , respectively. There was a sharp decline of log cfu value within 100 to $250 \mu \mathrm{g} / \mathrm{mL}$ SDS $(P<0.05)$. The results indicated that SDS treatment inhibited the amplification of DNA from culturable cells when its final concentration was greater than $100 \mu \mathrm{g} / \mathrm{mL}$. Therefore, the concentration of $100 \mu \mathrm{g} / \mathrm{mL}$ was selected as the optimal concentration for enhancing PMA to dead $E$. coli but it does not have influence on the culturable cells. After optimizing the SDS concentration, the effects of PMA treatment were assessed using the qPCR format. The $\mathrm{Cq}$ values with standard deviations are shown in Figure 2, and the optimal concentration was chosen as the one having the highest $\mathrm{Cq}$ value ( $\mathrm{Li}$ et al., 2015). For PMA concentrations of $0,10,20,30,40$, and $50 \mu M$, the $\mathrm{Cq}$ values of $E$. coli were 20.45, 20.68, 20.73, 21.45, 23.68, and 23.12, respectively. According to the $\mathrm{Cq}$ value, $40 \mu \mathrm{M}$ PMA was chosen as optimum concentration to inhibit amplification of DNA from dead cells without affecting the detection of culturable E. coli in the subsequent assay. The PMA coupled with qPCR is a useful tool compared with the traditional culture method for quantify viable cells (Wang et al., 2015; Xiao et al., 2015; Truchado et al., 2016). Up to now, PMA has been used successfully on several microorganisms (Wang et al., 2014; Li et al., 2015; Xiao et al., 2015). The PMA-qPCR penetrated only E. coli dead cells and eliminated false-positive results. Some researchers have reported that the intercalating dye is unable to penetrate viable bacteria when it is at a high concentration, resulting in partial DNA loss (Nocker et al., 2006; Kobayashi et al., 2009). Therefore, it was suggested that lower dye concentrations and shorter incubation time should be considered (Fittipaldi et al., 2012). The results of this study showed that $40 \mu M$ PMA can be used to inhibit the DNA amplification from dead cells when combined with dye incubation at $40^{\circ} \mathrm{C}$ for $20 \mathrm{~min}$ as described by $\mathrm{Li}$ et al. (2015) with slight modifications. Some research has indicated that the mixtures of viable cells and high concentration of dead cells can reduce the effect of PMA (Varma et al., 2009; Elizaquível et al., 2012a). This could be due to the presence of some special cells, which have an intact membrane but are not culturable, inhibiting the effect of PMA treatment (Nocker and Camper, 2009). The differences in PMA concentrations may be due to the differences in primers because DNA sequence might affect the amplification signal suppression from dead cells (Fittipaldi et al., 2012). However, the intercalating dyes cannot always suppress signals from dead cells in some special conditions, such as bacterial cells exposed to mild heat stress, high concentrations of cells, and the natural presence of PMA inhibitors (Li et al., 2015; Takahashi et al., 2017), which shows that not all DNA from dead cells were inhibited by PMA during the amplification phase. Thus, general PMA-qPCR cannot completely eliminate interference from dead cells.

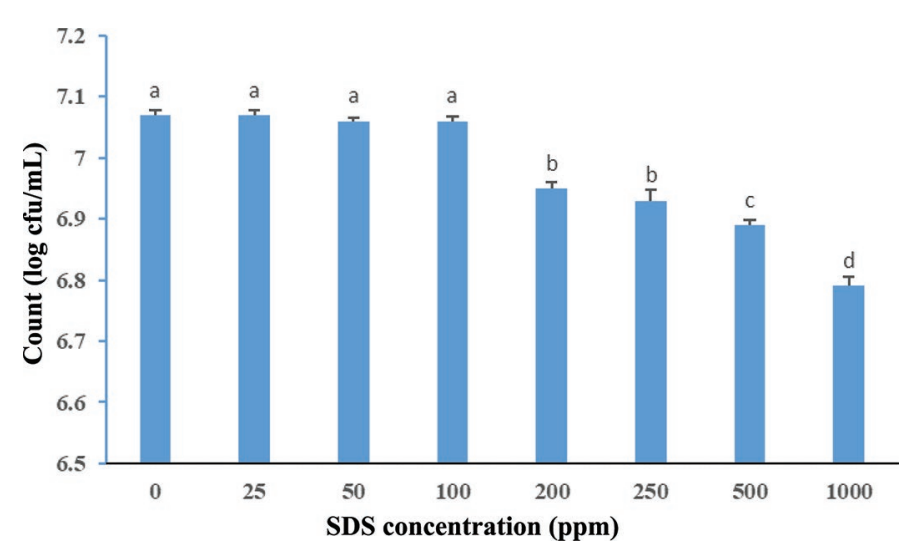

Figure 1. Optimization of SDS concentration. Samples of $1 \times 10^{7}$ cfu/mL of Escherichia coli were treated with different SDS concentrations $(0,25,50,100,200,250,500$, and $1,000 \mu \mathrm{g} / \mathrm{mL})$; the error bars indicate SD. Means with different letters $(\mathrm{a}-\mathrm{d})$ differ $(P<0.05)$. 


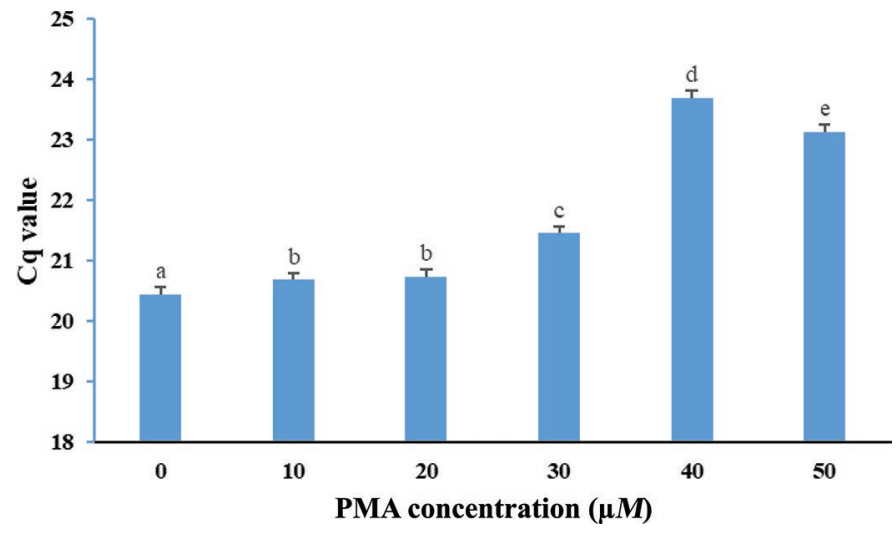

Figure 2. Optimization of propidium monoazide (PMA) concentration that inhibits amplification of dead Escherichia coli cells. Before PMA treatment, cell mixtures were prepared by mixing $1 \mathrm{~mL}$ of culturable cells with $1 \mathrm{~mL}$ of killed cells followed by the optimized concentration of SDS treatment. Cells were exposed to PMA at concentrations of $0,10,20,30,40$, and $50 \mu M$. The error bars indicate SD. Means with different letters $(\mathrm{a}-\mathrm{e})$ differ $(P<0.05) . \mathrm{Cq}=$ quantitative cycle.

To overcome this shortcoming, SDS was applied to enhance the effect of PMA in our study (Figure 1). The SDS, frequently used as an anionic surfactant, was incubated with the cells before PMA and applied to enhance permeability of dead cells to PMA. It has no influence on viable cells (Takahashi et al., 2017). Our results indicated that incubation with $100 \mu \mathrm{g} / \mathrm{mL}$ SDS at $37^{\circ} \mathrm{C}$ for $20 \mathrm{~min}$ has no significant effect on culturable $E$. coli cells (Figure 1); therefore, we chose $100 \mu \mathrm{g} /$ $\mathrm{mL}$ as the optimum amount. The same condition was reported by Takahashi et al. (2017), who found that $250 \mu \mathrm{g} / \mathrm{mL}$ was optimum to detect E. coli that could disrupt membranes of dead cells but had no effect on viable cells. Besides SDS, sodium lauroyl sarcosinate (Wang et al., 2014) and sarkosyl (Li et al., 2015) were also improved to increase the permeability of dead cell membranes to PMA.

Three replicates were analyzed for the efficiency evaluation of the qPCR in pure culture. A qPCR system with efficiency of 90 to $110 \%$ and $\mathrm{R}^{2}$ higher than 0.95 is generally considered acceptable (Zhang and Fang, 2006). In our standard curves, the correlation $\left(\mathrm{R}^{2}\right)$ was greater than 0.99 , showing a good linear relationship in the range of $10^{2}$ to $10^{7} \mathrm{cfu} / \mathrm{mL}$ (Figure 3 ). The slope of this standard curve was -3.311 for $E$. coli. The amplification efficiency for E. coli was $100.5 \%$.

In addition, detection of $E$. coli in milk without interference from dead organisms was developed and tested in combination with IAC. The IAC was added to the PCR to eliminate possible false-negative results caused by incorrect operation, improper PCR system, malfunction of the instrument (Zhu et al., 2005), and potential PCR inhibitors of the food matrix, such as infant food (Cortimiglia et al., 2016), food products (Wang et al., 2015), milk (Li et al., 2015), and environment water (Chiao et al., 2014). In our study, the DNA of $B$. cereus was chosen as the IAC, which could improve the reliability of false-negative results from the SDS-PMA-qPCR assay on milk samples. It is reported that some researchers have used $16 \mathrm{~S}$ rRNA as the IAC (Xu et al., 2011; Li et al., 2015; Wang et al., 2015); however, the 16S rRNA primer may compete with the specific primer for target DNA, thus affecting sensitivity of the qPCR assay. To prevent IAC from combining with the target for primers and to simplify the method of preparing the template of IAC, $B$. cereus DNA was chosen to eliminate the combination of target primers in our assay.

The sample application of the SDS-PMA-qPCR assay for $E$. coli was evaluated in artificially spiked milk (Figure 4). When milk samples were inoculated with $3 \times 10^{2} \mathrm{cfu} / \mathrm{mL}$ of culturable cells, the $\mathrm{Cq}$ values were 27.87 with SDS and PMA treatment, and 27.89 without SDS and PMA treatment (Figure 4a). When milk samples had $3 \times 10^{2} \mathrm{cfu} / \mathrm{mL}$ of culturable $E$. coli cells and $3 \times 10^{3} \mathrm{cfu} / \mathrm{mL}$ of dead cells, the $\mathrm{Cq}$ values were 27.78 with SDS and PMA treatment, and 24.10 without SDS and PMA treatment (Figure $4 \mathrm{~b})$. The Cq value of combinations with SDS and PMA treatment was higher than that of combinations without SDS and PMA treatment. After SDS and PMA treatment, the $\mathrm{Cq}$ value (27.78) was similar to the $\mathrm{Cq}$ value $(28.87)$ from the sample inoculated with only $3 \times 10^{2} \mathrm{cfu} / \mathrm{mL}$ of culturable cells. When milk samples were inoculated with $3 \times 10^{3} \mathrm{cfu} / \mathrm{mL}$ of culturable cells and $3 \times 10^{2}$ $\mathrm{cfu} / \mathrm{mL}$ of dead cells (Figure $4 \mathrm{c}$ ), the Cq values were 23.20 and 23.03, respectively, with and without SDS and PMA treatment for samples.

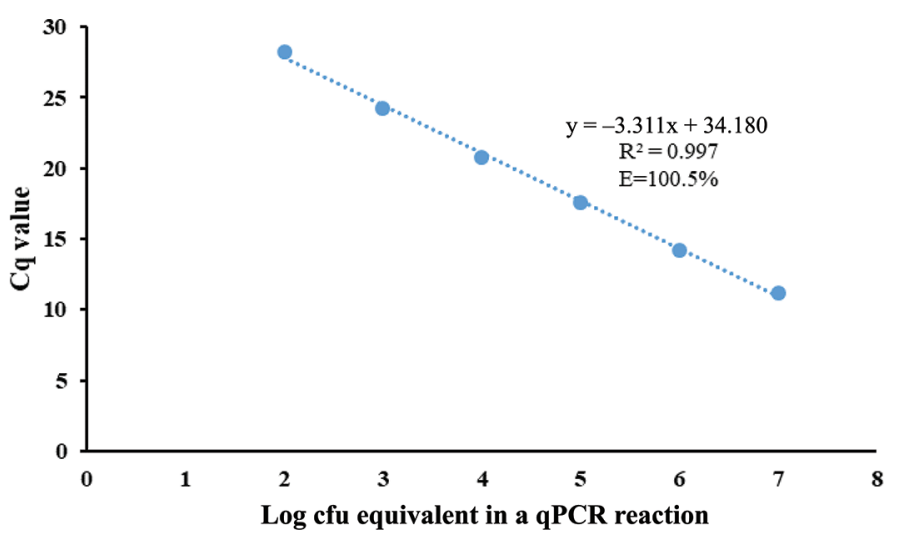

Figure 3. The amplification efficiencies (E) of SDS-propidium monoazide (PMA)-quantitative real-time PCR (qPCR) for Escherichia coli. Standard curve of the SDS-PMA-qPCR method for E. coli in pure culture. The DNA templates were diluted from $1.2 \times 10^{7}$ to $1.2 \times 10^{1}$ $\mathrm{cfu} / \mathrm{mL}$. The detection limit was $10^{2} \mathrm{cfu} / \mathrm{mL}$. Cq $=$ quantitative cycle. 


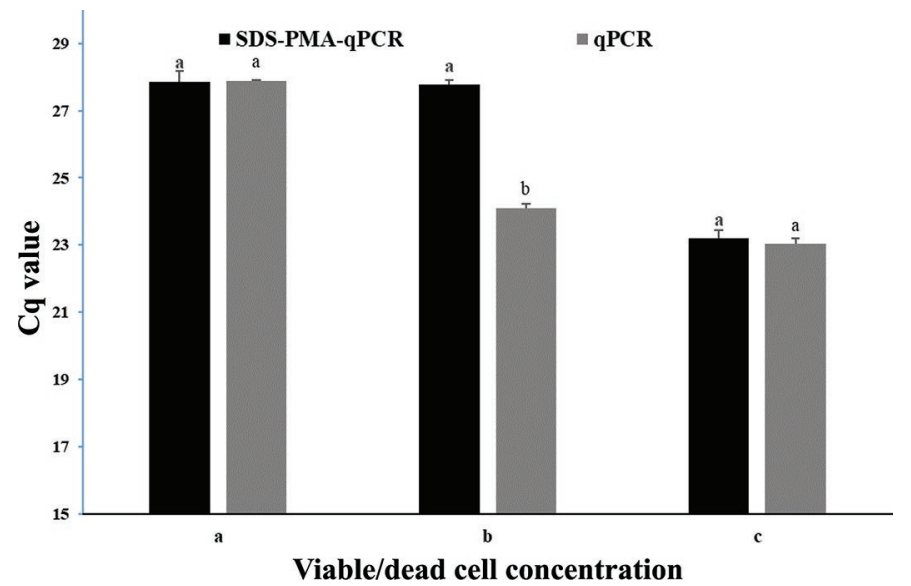

Figure 4. Detection of culturable Escherichia coli in spiked milk using SDS-propidium monoazide (PMA)-quantitative real-time PCR (qPCR). The samples were treated with PMA (black bars) or not treated (gray bars). Milk samples were inoculated with (a) $3 \times 10^{2}$ $\mathrm{cfu} / \mathrm{mL}$ of culturable cells; (b) $3 \times 10^{2} \mathrm{cfu} / \mathrm{mL}$ of culturable cells and 3 $\times 10^{3} \mathrm{cfu} / \mathrm{mL}$ of dead cells; and (c) $3 \times 10^{3} \mathrm{cfu} / \mathrm{mL}$ of culturable cells and $3 \times 10^{2} \mathrm{cfu} / \mathrm{mL}$ of dead cells. All tests were carried out in duplicate. Methods for the preparation of dead cells and mixing culturable and dead cells are described in the main text. Means with different letters $(\mathrm{a}, \mathrm{b})$ differ $(P<0.05) . \mathrm{Cq}=$ quantitative cycle.

It has been reported that some researchers used qPCR for detecting E. coli in some food samples (Zhu et al., 2005; Yoshitomi et al., 2012; Takahashi et al., 2017). Wang et al. (2014) used immunomagnetic separation with PMA-PCR to detect $5 \times 10^{3} \mathrm{cfu} / \mathrm{mL}$ of $E$. coli in spiked milk. Zhu et al. (2005) also established a rapid detection method to detect $E$. coli by using immunomagnetic separation and real-time PCR, the lowest detection limit was $3.3 \times 10^{2} \mathrm{cfu} / \mathrm{mL}$. In our assay, the limit of detection of this method was $10^{2} \mathrm{cfu} /$ $\mathrm{mL}$ in pure culture bacteria. Thus, we chose $3 \times 10^{2}$ and $3 \times 10^{3} \mathrm{cfu} / \mathrm{mL}$ of $E$. coli to validate sensitivity of the SDS-PMA-qPCR. From Figure 4, significant differences between the SDS-PMA-qPCR and qPCR $(P$ $<0.05$, Figure 4) indicated that the differences were caused by the presence of dead cells.

It is also beneficial to detect viable but nonculturable cells (VBNC), a special state in addition to the wellinvestigated bacterial growth phases, as VBNC might maintain their pathogenic gene and regain their ability to grow under favorable conditions, and thus pose a potential health risk (Jiang et al., 2013). Conventional culture-based methods are time consuming and fail to detect VBNC cells. Thus, another rapid detection method has to be developed to distinguish VBNC cells from dead ones.

In conclusion, we developed a specific, sensitive, and effective SDS-PMA-qPCR assay in combination with IAC for quantification detection of culturable $E$. coli in milk. This assay can reliably detect $10^{2} \mathrm{cfu} / \mathrm{mL}$ of culturable E. coli in milk. As far as we know, this is the first study using SDS-PMA-qPCR with IAC to detect culturable E. coli in milk. Therefore, this improved SDS-PMA-qPCR assay represents a suitable technique for improving the safety of milk potentially contaminated with $E$. coli.

\section{ACKNOWLEDGMENTS}

This research was supported by the Special Fund for Agro-Scientific Research in the Public Interest (Beijing, China; 201403071), Project of Risk Assessment on Raw Milk (Beijing, China; GJFP2018008), Fundamental Research Funds for the Central Non-Profit Research Institution (Beijing, China; 2018-YWFRW-18), the Agricultural Science and Technology Innovation Program (Beijing, China; ASTIP-IAS12), and the Modern Agro-Industry Technology Research System of China (Beijing, China; CARS-36).

\section{REFERENCES}

Chiao, T. H., T. M. Clancy, A. Pinto, C. Xi, and L. Raskin. 2014 Differential resistance of drinking water bacterial populations to monochloramine disinfection. Environ. Sci. Technol. 48:4038-4047.

Cortimiglia, C., M. Luini, V. Bianchini, L. Marzagalli, F. Vezzoli, D. Avisani, M. Bertoletti, A. Ianzano, A. Franco, and A. Battisti. 2016. Prevalence of Staphylococcus aureus and of methicillin-resistant $S$. aureus clonal complexes in bulk tank milk from dairy cattle herds in Lombardy Region (northern Italy). Epidemiol. Infect. 144:3046-3051.

Dong, L., H. M. Liu, L. Meng, M. R. Xing, J. Q. Wang, C. Wang, H. Chen, and N. Zheng. 2018. Quantitative PCR coupled with sodium dodecyl sulfate and propidium monoazide for detection of viable Staphylococcus aureus in milk. J. Dairy Sci.101:4936-4943.

Elizaquível, P., G. Sánchez, and R. Aznar. 2012a. Quantitative detection of viable foodborne E. coli, O157:H7, Listeria monocytogenes, and Salmonella, in fresh-cut vegetables combining propidium monoazide and real-time PCR. Food Control 25:704-708.

Farrokh, C., K. Jordan, F. Auvray, K. Glass, H. Oppegaard, S. Raynaud, D. Thevenot, R. Condron, K. De Reu, A. Govaris, K. Heggum, M. Heyndrickx, J. Hummerjohann, D. Lindsay, S. Miszczycha, S. Moussiegt, K. Verstraete, and O. Cerf. 2013. Review of Shiga-toxin-producing Escherichia coli (STEC) and their significance in dairy production. Int. J. Food Microbiol. 162:190-212.

Fittipaldi, M., A. Nocker, and F. Codony. 2012. Progress in understanding preferential detection of live cells using viability dyes in combination with DNA amplification. J. Microbiol. Methods 91:276-289.

Jiang, Q., B. Fu, Y. Chen, Y. Wang, and H. Liu. 2013. Quantification of viable but nonculturable bacterial pathogens in anaerobic digested sludge. Appl. Microbiol. Biotechnol. 97:6043-6050.

Kobayashi, H., M. Oethinger, M. J. Tuohy, G. S. Hall, and T. W. Bauer. 2009. Unsuitable distinction between viable and dead Staphylococcus aureus and Staphylococcus epidermidis by ethidium bromide monoazide. Lett. Appl. Microbiol. 48:633-638.

Li, H., H. Xin, and S. F. Li. 2015. Multiplex PMA-qPCR assay with internal amplification control for simultaneous detection of viable Legionella pneumophila, Salmonella typhimurium, and Staphylococcus aureus in environmental waters. Environ. Sci. Technol. 49:14249-14256.

Maheux, A. F., F. J. Picard, M. Boissinot, L. Bissonnette, S. Paradis, and M. G. Bergeron. 2009. Analytical comparison of nine PCR 
primer sets designed to detect the presence of Escherichia coli/ Shigella in water samples. Water Res. 43:3019-3028.

National Health and Family Planning Commission of PRC, China Food and Drug Administration. 2016. GB4789.2-2016: National Food Safety Standard Food Microbiology Detection Total Bacterial Count. National Standards of the People's Republic of China, Beijing.

New Zealand Food Safety Authority. 2008. DPC2: Animal Products (Dairy) Approved Criteria for Farm Dairies. New Zealand Food Safety Authority, Wellington.

Nocker, A., and A. K. Camper. 2009. Novel approaches toward preferential detection of viable cells using nucleic acid amplification techniques. FEMS Microbiol. Lett. 291:137-142.

Nocker, A., C. Y. Cheung, and A. K. Camper. 2006. Comparison of propidium monoazide with ethidium monoazide for differentiation of live vs. dead bacteria by selective removal of DNA from dead cells. J. Microbiol. Methods 67:310-320.

Pavlovic, M., A. Luze, R. Konrad, A. Berger, and I. Huber. 2011. Development of a duplex real-time PCR for differentiation between E. coli and Shigella spp. J. Appl. Microbiol. 110:1245-1251.

Takahashi, H., Y. Gao, S. Miya, T. Kuda, and B. Kimura. 2017. Discrimination of live and dead cells of Escherichia coli, using propidium monoazide after sodium dodecyl sulfate treatment. Food Control 71:79-82.

Truchado, P., M. I. Gil, T. Kostic, and A. Allende. 2016. Optimization and validation of a PMA qPCR method for quantification in primary production. Food Control 62:150-156.

Varma, M., R. Field, M. Stinson, B. Rukovets, L. Wymer, and R. Haugland. 2009. Quantitative real-time PCR analysis of total and propidium monoazide-resistant fecal indicator bacteria in wastewater. Water Res. 43:4790-4801.

Wang, L., P. Li, Z. Zhang, Q. Chen, Z. P. Aguilar, and H. Xu. 2014 Rapid and accurate detection of viable Escherichia coli, O157:H7 in milk using a combined IMS, sodium deoxycholate, PMA and real-time quantitative PCR process. Food Control 36:119-125.

Wang, L., C. Ye, H. Xu, Z. P. Aguilar, Y. Xiong, and W. Lai. 2015. Development of an SD-PMA-mPCR assay with internal amplification control for rapid and sensitive detection of viable Salmonella, spp., Shigella spp. and Staphylococcus aureus in food products. Food Control 57:314-320.

Wang, Y., P. Zhao, H. Zhang, W. Chen, X. Su, and B. Suo. 2013. A simple and rapid realtime PCR assay for the detection of Shigella, and Escherichia coli, species in raw milk. J. Verbraucherschutz Lebensmsicherh. 8:313-319.

Xiao, L., Z. Zhang, X. Sun, Y. Pan, and Y. Zhao. 2015. Development of a quantitative real-time PCR assay for viable Salmonella spp. without enrichment. Food Control 57:185-189.

Xu, H., Z. P. Aguilar, L. Yang, M. Kuang, H. Duan, and Y. Xiong. 2011. Antibody conjugated magnetic iron oxide nanoparticles for cancer cell separation in fresh whole blood. Biomaterials 32:9758.

Yoshitomi, K. J., K. C. Jinneman, R. Zapata, S. D. Weagant, and W. M. Fedio. 2012. Detection and isolation of low levels of E. coli O157:H7 in cilantro by real-time PCR, immunomagnetic separation, and cultural methods with and without an acid treatment. J. Food Sci. 77:M481-M489.

Zhang, T., and H. H. Fang. 2006. Applications of real-time polymerase chain reaction for quantification of microorganisms in environmental samples. Appl. Microbiol. Biotechnol. 70:281-289.

Zhang, Z., L. Wang, H. Xu, Z. P. Aguilar, C. Liu, and B. Gan. 2014 Detection of non-emetic and emetic Bacillus cereus, by propidium monoazide multiplex PCR (PMA-mPCR) with internal amplification control. Food Control 35:401-406.

Zhu, F., S. Rogelj, and T. L. Kieft. 2005. Rapid detection of Escherichia coli, O157:H7 by immunomagnetic separation and real-time PCR. Int. J. Food Microbiol. 99:47-57. 